\title{
NOTES
}

At the meeting of the International Astronomical Union, held at Rome, May 2-10, 1922, Dr. W. W. Campbell, of the Lick Observatory, was elected president for the coming three years. Professor Tuliio Levi Civita was appointed chairman of the committee on relativity.

The Jablonowski Society announces the following prize problem for 1924: In extending the Gaussian algorithm of the arithmetic-geometric mean to the case of two arbitrary functions $\varphi(x, y)$ and $\psi(x, y)$ two infinite sequences $x, x_{1}, \cdots, x_{n}, \cdots, y, y_{1}, \cdots, y_{n}, \cdots$ are obtained, starting from any two numbers $x$ and $y$, by means of the recurrence formulas $x_{n}=\varphi\left(x_{n-1}, y_{n-1}\right), y_{n}=\psi\left(x_{n-1}, y_{n-1}\right)$. The Society desires a discussion of such sequences for some simple functions $\varphi(x, y)$ and $\psi(x, y)$ for which an independent representation of the members of the sequences defined by the recurrence formulas can be found. Competing memoirs should be sent to the Jablonowski Society at the Library of the University of Leipzig before October 31, 1924; they should be written in German, Latin, or French.

Professor Henri Lebesgue, of the Sorbonne, has been elected a member of the Paris Academy of Sciences in the section of geometry, as successor to the late Camille Jordan.

Princeton University has conferred the honorary degree of doctor of science on Professor A. G. Webster, of Clark University.

Mr. W. W. Rouse Ball, of Trinity College, Cambridge, has offered to the University a sum of $£ 500$ to constitute a trust fund for the provision of occasional lectures dealing either with some particular development of mathematics or with some application of mathematics to science.

The Royal Society of Edinburgh has conferred its Keith prize (19191921) on Professor R. A. Sampson for his astronomical researches, including his papers on Studies in clocks and time keeping, published in its ProceedINGS during the period of the award. The same Society has conferred its James Scott prize, established in 1918 for a lecture or essay on the fundamental concepts of natural philosophy, on Professor A. N. Whitehead, for his lecture entitled The relatedness of nature.

The British commissioners of 1851 announce the following appointments to senior studentships in mathematics for 1922: Mr. A. E. Ingham, research student, Cambridge University; Mr. J. F. Jones, lecturer, University of Manchester. Holders of these studentships are given the opportunity of devoting their whole time for a period of not less than two years to scientific research.

The following advanced courses in mathematics are announced for the academic year 1922-23:

University of Chicago.-All courses meet four times a week for a quarter of twelve weeks. Courses which continue for more than one quarter are indicated with Roman numerals, as I, II, III, or IV.-By 
Professor E. H. Moore: Vectors, matrices, and quaternions; Matrices in general analysis I, II, III, IV.-By Professor L. E. Dickson: Theory of numbers I, II; Solid analytics; Theory of equations.-By Professor H. E. Slaught: Differential equations; Elliptic integrals; Calculus I.By Professor G. A. Bliss: Definite integrals; Elliptic functions; Calculus II, III.-By Professor E. J. Wilczynski: Projective differential geometry I, II; Functions of a complex variable; Calculus I, II.-By Professor F. R. Moulton: Analytic differential equations I, II, III; Advanced ballistics I, II, III.-By Professor W. D. MacMillan: Analytic mechanics I, II, III; Celestial mechanics.-By Professor A. C. Lunn: Units and dimensions; Dynamics of continuous media; Canonical equations and quantum theory; Thermodynamics.-By Dr. Mayme I. Logsdon: Theory of algebraic invariants; Calculus I, II, III.-By Professor J. W. A. Young: Limits and series. Courses in research are also offered by Professor Moore in Foundations of mathematics and in General analysis, by Professor Bliss in Analysis, by Professor Dickson in Algebra and Theory of numbers, by Professor Wilczynski in Geometry, and by Professor Lunn in Applied mathematics.

University of Illinois.-By Professor E. J. Townsend: Real variables.-By Professor G. A. Miller: Finite groups.-By Professor J. B. Shaw: Linear operators.-By Professor A. B. Coble: Differential geometry.-By Professor R. D. Carmichael: Linear differential equations in real variables.-By Professor A. Emch: Automorphic functions.-By Professor A. R. Crathorne: Theory of statistics.-By Professor A. J. Kempner: Modern algebra.-By Professor H. Blumberg: Introduction to higher mathematics.

Johns Hopkins University.-By Professor F. Morley: Higher geometry (first term); Theory of functions (second term).-By Professor A. Cohen: Applications of calculus, differential equations, and mechanics.By Professor L. S. Hulburt: Advanced calculus; Projective geometry and higher plane curves.-By Dr. J. R. Musselman: Elementary theory of probability.-Professor Morley will conduct a seminary and a reading class.

Massachusetts Institute of Technology.-By Professor F. S. Woods: Advanced calculus.-By Professor C. L. E. Moore: Theoretical aeronautics.-By Professor H. B. Phillips: Thermodynamics.-By Professor J. Lipka: Analytical mechanics.-By Dr. N. Wiener: Fourier's series and integral equations.-By Dr. George Rutledge: Theory of functions.-By Dr. S. D. Zeldin: Vector analysis.-By Dr. J. S. Taylor: Mathematics of investment.

University of Michigan.-By Professor J. L. Markley: Solid analytic geometry (first term); Theory of functions of a complex variable; Theory of functions of real variables.-By Professor J. W. Glover: Theory of probability (first term); Finite differences (second term); Advanced mathematical theory of interest and life contingencies.-By Professor W. B. Ford: Advanced calculus, with especial reference to Fourier series and harmonic analysis; Infinite series and products; Elements of the calculus of variations (first term).-By Professor L. C. Karpinski: Higher algebra; Theory of numbers; History of mathematics.-By Professor 
J. W. Bradshaw: Introduction to modern geometry (second term); Projective geometry.-By Professor R. B. Robbins: Casualty actuarial theory. -By Mr. R. W. Barnard: Differential equations (first term); Mathematical theory of statistics, advanced course.-By Professor A. Ziwet: Hydrodynamics.-By Professor P. Field: Projective geometry for engineers (first term); Vector analysis (second term).-By Professor T. R. Running: Graphical methods (first term); Empirical formulas (second term); Advanced calculus (first term).-By Professor T. E. Hildebrandt: Theory of the potential (first term).-By Professor V. C. Poor: Theoretical mechanics.-By Professor L. J. Rouse: Fourier series (second term).

University of Pennsylvania.-By Professor E. S. Crawley: Modern analytic geometry (first term); Differential equations (first term); Higher plane curves (second term).-By Professor G. H. Hallett: Infinite series and products (first term); Functions of a complex variable (second term). -By Professor H. B. Evans: Quaternions and vector methods (second term).-By Professor O. E. Glenn: Calculus of variations.-By Professor F. H. Safford: Mathematical theory of elasticity.-By Professor G. G. Chambers: Introduction to higher algebra.-By Professor H. H. Mitchell: Linear groups (first term); Advanced calculus (second term).-By Professor M. J. Babb: History of mathematics.-By Professor F. W. Beal: Differential geometry.-By Professor J. R. Kline: Foundations of mathematics (first term); Continuous transformations (second term).

University of Wisconsin.-By Professor E. P. Lane: Modern analytical geometry.-By Professor E. B. Van Vleck: Functions of a real variable; Integral equations.-By Professor H. W. March: Theoretical hydrodynamics.-By Professor C. S. Slichter: Potential theory.-By Professor E. B. Skinner: Higher algebra.-By Professor A. Dresden: Calculus of variations.

Yale University.-By Professor E. W. Brown: Mechanics; Advanced mechanics; Hydromechanics.-By Professor J. Pierpont: Functions of a complex variable; Projective and differential geometry; Approximation methods.-By Professor P. F. Smith: Differential equations.-By Professor W. A. Wilson: Theory of aggregates.-By Professor E. J. Miles: Advanced calculus; Calculus of variations.-By Professor J. I. Tracey: Advanced analytic geometry.-By Professor W. L. Crum: Mathematical statistics.-By Professor J. K. Whittemore: Advanced differential geometry.

Professor A. Sommerfeld, professor of mathematical physics at the University of Munich, will be in residence at the University of Wisconsin for the first semester of the coming academic year. He will hold during that period the Karl Schurz Memorial Professorship, which was established at the University of Wisconsin in 1910, and is resumed with this appointment after the interruption caused by the war. Professor Sommerfeld is expected to offer a three-hour course on Atomic structure, and a three-hour course either on the Analysis of wave propagation, or on the General theory of relativity. Professor Sommerfeld is known to American scholars in pure mathematics as well as to those in mathematical physics. 
Professor L. Tonelli, of the University of Parma, has been appointed professor of higher analysis at the University of Bologna.

Professor L. Silla, of the University of Cagliari, has been appointed professor of rational mechanics at the University of Genoa.

Professor E. Bertini, of the University of Pisa, has retired from active service.

At the University of Lille, Professor A. Chatelet has been transferred from the professorship of general mathematics to that of rational mechanics; Dr. Gambier succeeds him as professor of general mathematics.

At Cambridge University, Mr. E. A. Milne, of Trinity College, has been appointed University lecturer in astrophysics, and Mr. S. Lees, of St. John's College, University lecturer in thermodynamics.

Professor W. R. Burwell, of the University of Tennessee, has been appointed assistant professor of mathematics and dean of freshmen at Brown University.

Professor K. D. Swartzel, formerly of the University of Ohio, has been appointed head of the department of mathematics at the University of Pittsburgh.

Miss Helen Barton, of Wellesley College, has been appointed dean of women at Albion College.

Mr. W. H. Hill, of the University of Colorado, has been appointed assistant professor of mathematics at the Manual Training Normal School, Pittsburg, Kansas.

Mr. H. K. Cummings has resigned his instructorship in mathematics at Brown University to accept a position in the Bureau of Standards at Washington.

At Iowa State College, Associate Professor J. T. Colpitts has been granted leave of absence for the coming year to study at Cornell University; Assistant Professor E. C. Kiefer has been granted leave of absence for the coming year to study at the University of Michigan; Dr. H. C. Gossard, formerly of the University of Oklahoma and the U. S. Naval Academy, has been appointed to an assistant professorship.

Professor W. J. Risley has resigned as professor of mathematics at James Millikan University, where he has been since 1910, to accept a position as head of the department of mathematics at the Colorado School of Mines.

Professor William Marshall, who has been acting head of the department of mathematics at Purdue University during the past year, has been appointed head of the department there.

At the California Institute of Technology, Professor Harry Bateman, formerly professor of aeronautical research and mathematical physics, has been made professor of mathematics, theoretical physics, and aeronautics; Dr. Clyde Wolfe, formerly instructor, has been made assistant professor of mathematics; Dr. R. C. Tolman has been appointed professor of physical chemistry and mathematical physics. 
At the University of Manitoba, Mr. F. S. Nowlan has been promoted to an assistant professorship of mathematics.

Professor J. D. Bond, of Louisiana State University, has been appointed associate professor of mathematics at the University of Tennessee.

At the University of Colorado, Assistant Professor G. H. Light has been promoted to a full professorship and Dr. Claribel Kendall to an assistant professorship.

At the University of Washington, Associate Professor E. T. Bell has been promoted to a full professorship and Dr. L. L. Smail to an assistant professorship. Dr. Hermance Mullemeister has been granted a year's leave of absence for study in Holland; her place will be taken by Miss E. D. Pepper.

Assistant Professor R. B. Robbins will return to the University of Michigan after two years' absence in actuarial work in the departments of insurance of Missouri and New York.

At the University of California, Professor C. A. Noble has been granted a term's leave of absence, which he will spend in Europe.

At the Georgia School of Technology, Professor B. M. Boerckel has resigned and Mr. R. M. Mundorff has been appointed assistant professor.

At Dartmouth College, Assistant Professor F. M. Morgan has resigned.

The following appointments to instructorships at American colleges and universities are announced:

Brown University, Mr. J. H. Fithian, Mr. H. C. Hicks, Mr. A. O. Hickson;

University of California, Dr. P. H. Daus (transferred to southern branch), Dr. B. C. Wong;

Carnegie Institute of Technology, Mr. George Parks;

Dartmouth College, Dr. B. H. Brown;

Georgia School of Technology, Mr. H. K. Fuhner;

Hood College, Miss M. C. Packer;

University of Iowa, Mr. R. E. Kennon;

Iowa State College, Mr. R. G. Robinson;

University of Michigan, Mr. R. V. Churchill, Mr. C. C. Craig;

University of Missouri, Mr. C. G. Jaeger;

University of Nebraska, Mr. F. S. Harper;

New York University, Mr. F. W. John;

University of Pennsylvania, Mr. J. M. Thomas;

Pennsylvania State College, Mr. R. H. Marquis;

Purdue University, Dr. W. E. Edington, Mr. W. J. Wagner;

Randolph-Macon College, Mr. J. W. Blincoe;

Smith College, Miss Constance Wiener;

Syracuse University, Miss May Sperry;

Wellesley College, Miss F. M. Merriam;

University of Wisconsin, Mr. E. B. Keller, Mr. A. H. Wait. 
Professor O. Tedone, of the University of Genoa, died April 18, 1922, at the age of fifty-two years.

Professor Hermann Grassmann, of the University of Giessen, died in January, 1922, at the age of sixty-five years.

Professor J. C. Kapteyn, professor of astronomy and mechanics at the University of Groningen, died June 18, 1922.

Professor Pierre Boutroux, of the Collège de France, died June 25, 1922. Professor Boutroux had been a member of the American Mathematical Society since 1913.

Professor James McMahon, of Cornell University, died June 1, 1922, at the age of sixty-six years. Professor McMahon had been a member of the American Mathematical Society since its organization (as the New York Mathematical Society) in 1891. He was for seven years associate editor of the Annals of Mathematics, and was secretary of section A, general secretary, and vice-president of the American Association for the Advancement of Science.

\section{NEW PUBLICATIONS}

\section{HIGHER MATHEMATICS}

Brnny (L. B.). Plane geometry. An account of the more elementary properties of the conic sections, treated by the methods of co-ordinate geometry, and of modern projective geometry, with applications to practical drawing. London, Blackie, 1922. $8+336 \mathrm{pp}$.

Bieberbach (I.). Funktionentheorie. (Teubners Technische Leitfäden, Band 14.) Leipzig, Teubner, 1922. $118 \mathrm{pp.}$

Borel (E.). See Lévy (P.).

Cartan (E.). Leçons sur les invariants intégraux. Paris, Hermann, 1922. $10+210 \mathrm{pp}$.

Denjoy (A.). Calcul des coefficients de la série trigonométrique convergente la plus générale dont la somme est une fonction donnée. Paris, Gauthier-Villars, 1921. 4to. 16 pp.

Goursat (E.). Leçons sur le problème de Pfaff. Paris, Hermann, 1922. $8+387$ pp.

HAAG (J.). Cours complet de mathématiques spéciales. Tome 2: Géométrie. Paris, Gauthier-Villars, 1921. 8vo. $6+662$ pp.

Hadamard (J.). See Juvet (G.), Lévy (P.).

Juver (G.). Introduction au calcul tensorial et au calcul différentiel absolu. Préface de M. J. Hadamard. Paris, Blanchard, 1922. 8vo. $2+101 \mathrm{pp}$.

Kowalewski (G.). Die klassischen Probleme der Analysis des Unendlichen. Ein Lehr- und Uebungsbuch für Studierende zur Einführung in die Infinitesimalrechnung. 2te Auflage. Leipzig, Engelmann, 1921. 8vo. $8+342 \mathrm{pp}$. 